\title{
Identification of mutans and other oral streptococci by random amplified polymorphic DNA analysis
}

\author{
T. L. TRUONG, C. MÉNARD*, C. MOUTON and L. TRAHAN
}

Groupe de Recherche en Écologie Buccale, Faculté de Médecine Dentaire, Université Laval, Québec G1K 7P4 and * Centre de Recherche en Infectiologie de I'Université Laval, CHUQ, Building CHUL, 2705 Blvd Laurier, Ste-Foy GIV 4G2, Canada

The identification and classification of the non-haemolytic or viridans group of streptococci have long been recognised as difficult and unsatisfactory. Phenotypic and genotypic heterogeneity have resulted in ambiguous speciation, particularly with mutans streptococci and other oral streptococci. This study was done to determine whether random amplified polymorphic DNA (RAPD) analysis is useful to identify and even classify oral and other streptococci. DNA was prepared and purified from 25 strains of mutans streptococci including 11 reference strains of Streptococcus mutans, seven of S. sobrinus, three of $\mathrm{S}$. rattus and one each of the four other species of the mutans group, together with 20 other reference species, mostly streptococci, and from 49 fresh isolates of mutans streptococci and of S. mutans from human saliva and dental plaque. DNA amplification was primed with each of three arbitrarily selected primers nine or 10 nucleotides in length. The amplified DNA fragments (amplicons) obtained were compared by agarose gel electrophoresis. Species- and strain-specific RAPD fingerprints were obtained not only from pure genomic DNA, but also from the supernates of crude cellular or colony extracts. Pending the analysis of numerous other strains, the data suggest that RAPD may be of value: (i) to distinguish the species $\mathrm{S}$. mutans and $\mathrm{S}$. sobrinus from each other and potentially from other species of oral streptococci, (ii) to differentiate and possibly classify oral streptococci and (iii) as a valuable tool in mutans streptococci epidemiology and transmission studies, by virtue of its rapidity, efficiency and reproducibility in generating genetic fingerprints of streptococcal isolates.

\section{Introduction}

The non-haemolytic or viridans group of streptococci make up a major component of the oral microbiota and may become opportunist pathogens. This group consists of several taxa and includes the group of mutans streptococci, formerly identified as Streptococcus mutans. Because $\mathrm{S}$. mutans was so genetically heterogeneous it was divided into seven species $[1,2]$. The most common member of mutans streptococci is $S$. mutans: most human beings harbour this streptococcus in dental plaque; a small percentage of people have $S$. sobrinus instead. S. rattus and S. cricetus can be found in some populations, but they are not common [3]. The other species - S. ferus, S. macacae and S. downei are

Received 4 May 1999; revised version received 15 July 1999; accepted 19 July 1999.

Corresponding author: Dr L. Trahan (e-mail: Luc.Trahan@ greb.ulaval.ca). found only in animals. The identification and classification of viridans streptococci have long been recognised as difficult and unsatisfactory $[4,5]$ and have relied on batteries of morphological observations, biochemical and physiological tests and antigenic reactions [6-11]. Because of the phenotypic and genotypic heterogeneity of oral streptococci, new species are continually proposed $[1,5,6,12,13]$. As phenotyping and serotyping rely on gene expression and, consequently, may be unstable, DNA-based characterisation is now widely accepted. Several molecular typing methods are presently available and some of them have been applied to oral streptococci $[14,15]$. They include DNA-DNA hybridisation $[1,12,14]$, restriction endonuclease analysis (REA) [16-19], multilocus enzyme electrophoresis (MLEE) [20], ribotyping, PCR and colony hybridisation with DNA probes [21]. A PCR-based procedure of DNA fingerprinting, called arbitrarily primed PCR (AP-PCR) [22] or randomly amplified polymorphic DNA (RAPD) analysis [23], has been applied to strain identification 
and typing of oral bacteria [24-27], oral streptococci [28-30] and non-oral streptococci [31-34]. The present study used RAPD analysis for typing $S$. mutans and $S$. sobrinus strains and to explore the potential of this typing method to distinguish these from the other taxa that comprise the group of mutans streptococci.

\section{M aterials and methods}

\section{Bacterial strains, maintenance and growth conditions}

The 45 bacterial strains used as reference in this study are listed in Table 1. They included 25 laboratory strains of mutans streptococci, 15 strains of other streptococci (mostly of oral origin) and 5 other unrelated species. A total of 49 clinical isolates was also studied, as shown in Table 1: 17 were dental plaque isolates (identified as mutans streptococci) from eight patients [17] provided by H. J. Sandham (University of Toronto) and 32 were isolated (characterised as $\mathrm{S}$. mutans) in this laboratory from the saliva of 23 young adults [35]. The strains were kept both lyophilised and cryoconserved at $-80^{\circ} \mathrm{C}$. B acterial cells were cultured at $37^{\circ} \mathrm{C}$ in $10 \mathrm{ml}$ of glucose $0.5 \%$ supplemented TYE medium containing (/L): trypticase (BBL M icrobiology Systems) $17 \mathrm{~g}$, yeast extract (Difco Laboratories) $3 \mathrm{~g}, \mathrm{NaCl} 5 \mathrm{~g}$ and disodium phosphate $2.5 \mathrm{~g}$. The purity and identity of the cultures used for the experiments were confirmed by Gram's stain, colony morphology on MSA (Difco) and on TYE agar containing glucose $0.5 \%$, sugar fermentation patterns and with the API Rapid Strep test (API Laboratory Products, St Laurent, Canada). No further characterisation of the 45 reference strains was performed and the identity of the 49 clinical strains was established as described elsewhere $[17,35]$.

\section{DNA isolation and purification}

Bacteria were harvested by centrifugation and their DNA was prepared and purified according to Chassy and Giuffrida [36] with some modifications. B riefly, the cell lysate obtained by lysozyme and SDS treatments was extracted three times with saturated phenol (Amresco, Solon, $\mathrm{OH}, \mathrm{USA}$ ) and once with a 1:1 mixture of phenol:chloroform (1:1). The cellular RNA was eliminated by an RNA ase treatment according to Smith et al. [37]. The total DNA was then collected by ethanol precipitation. The DNA content was calculated by measuring the absorbance at $260 \mathrm{~nm}$ and its quality was assessed by the $260: 280 \mathrm{~nm}$ absorbance ratio and by electrophoresis on agarose gel.

\section{Whole cell extraction}

Cells from overnight broth cultures $(50 \mu l)$ were harvested by centrifugation and $50 \mu \mathrm{l}$ of sterile Tris buffer $(10 \mathrm{mmol} / \mathrm{L}, \mathrm{pH} 8.2)$ were used to suspend the cell pellet obtained. Alternatively, colonies of generally
$<1 \mathrm{~mm}$ in diameter were individually transferred from agar plates into $50 \mu \mathrm{l}$ of the same buffer. Whole-cell lysates were then prepared by incubating the cell suspension with lysozyme (Sigma) $1 \mathrm{mg} / \mathrm{ml}$ at $37^{\circ} \mathrm{C}$ for $30 \mathrm{~min}$. The lysates were then extracted with an equal volume of saturated phenol at $55^{\circ} \mathrm{C}$ for $30 \mathrm{~min}$. The extracts were centrifuged and $5 \mu \mathrm{l}$ of supernate were used, without further purification, as a DNA template for the AP-PCR amplification reaction.

\section{Working primers and random amplification}

In preliminary experiments a total of 56 oligonucleotides (9-23 mer) were tested as primers for their capacity to amplify purified DNA of $\mathrm{S}$. mutans strain NCTC 10449. This allowed the selection of three working primers responding to the following criteria:RAPD profile should be visible and clear under UV light and the genetic fingerprint should be composed of amplicons sufficient in number and located between a range of standard DNA ladder. These working primers were: 970-11 (5'GTAAGGCCG) from our bank, OPA-3 (5'AGTCAGCCAC) and OPA-18 (5'AGGTGACCGT) from Operon Technologies (Alameda, CA, USA). A mplification reactions were performed as described previously [24]. The $25-\mu l$ reaction mixtures contained Tris- $\mathrm{HCl} 20 \mathrm{mmol} / \mathrm{L}, \mathrm{pH} 8.3, \mathrm{KCl} 50 \mathrm{mmol} / \mathrm{L}, \mathrm{M} \mathrm{gCl}_{2}$ $4 \mathrm{mmol} / \mathrm{L}$, gelatin $0.001 \%, 200 \mathrm{mmol} / \mathrm{L}$ each of $\mathrm{dATP}$, dCTP, dGTP and dTTP, 30 pmoles of primer, $50 \mathrm{ng}$ of purified DNA or $5 \mu \mathrm{l}$ of supernate of whole cell or colony extract, and $1.25 \mathrm{U}$ of Taq DNA polymerase (Pharmacia). The amplification was performed in a DNA thermal cycler (Perkin Elmer Cetus, M ontréal, Canada) programmed for 30 cycles of $1 \mathrm{~min}$ at $94^{\circ} \mathrm{C}$, $1 \mathrm{~min}$ at $32^{\circ} \mathrm{C}$ and $2 \mathrm{~min}$ at $72^{\circ} \mathrm{C}$. A negative control without DNA was included in each AP-PCR run. All such controls were always negative. Amplicons obtained were compared after electrophoresis on an agarose $1.5 \%$ gel (Seakem, Rockland, MA, USA) in Tris-acetate buffer, detection with ethidium bromide and photography under UV transillumination as described elsewhere [24].

\section{Results}

RAPD fingerprinting of the reference strains of $S$. mutans and $S$. sobrinus

Each of the RAPD patterns obtained with $S$. mutans reference strains with primers 970-11, OPA -3 and OPA 18 contained a set of major amplicons that were shared by almost all the strains; the three predominant banding patterns thus obtained were clearly distinct from those of several related (Fig. 1) and unrelated (Fig. 2) species. However, the RAPD fingerprints contained only a limited subset of amplicons that are indicative of genetic polymorphism within the species.

U se of primer $970-11$ yielded the simplest fingerprints, composed of two major amplicons at 1585 and $977 \mathrm{bp}$ 
Table 1. Species, strains, origins and sources of the bacteria used in the study

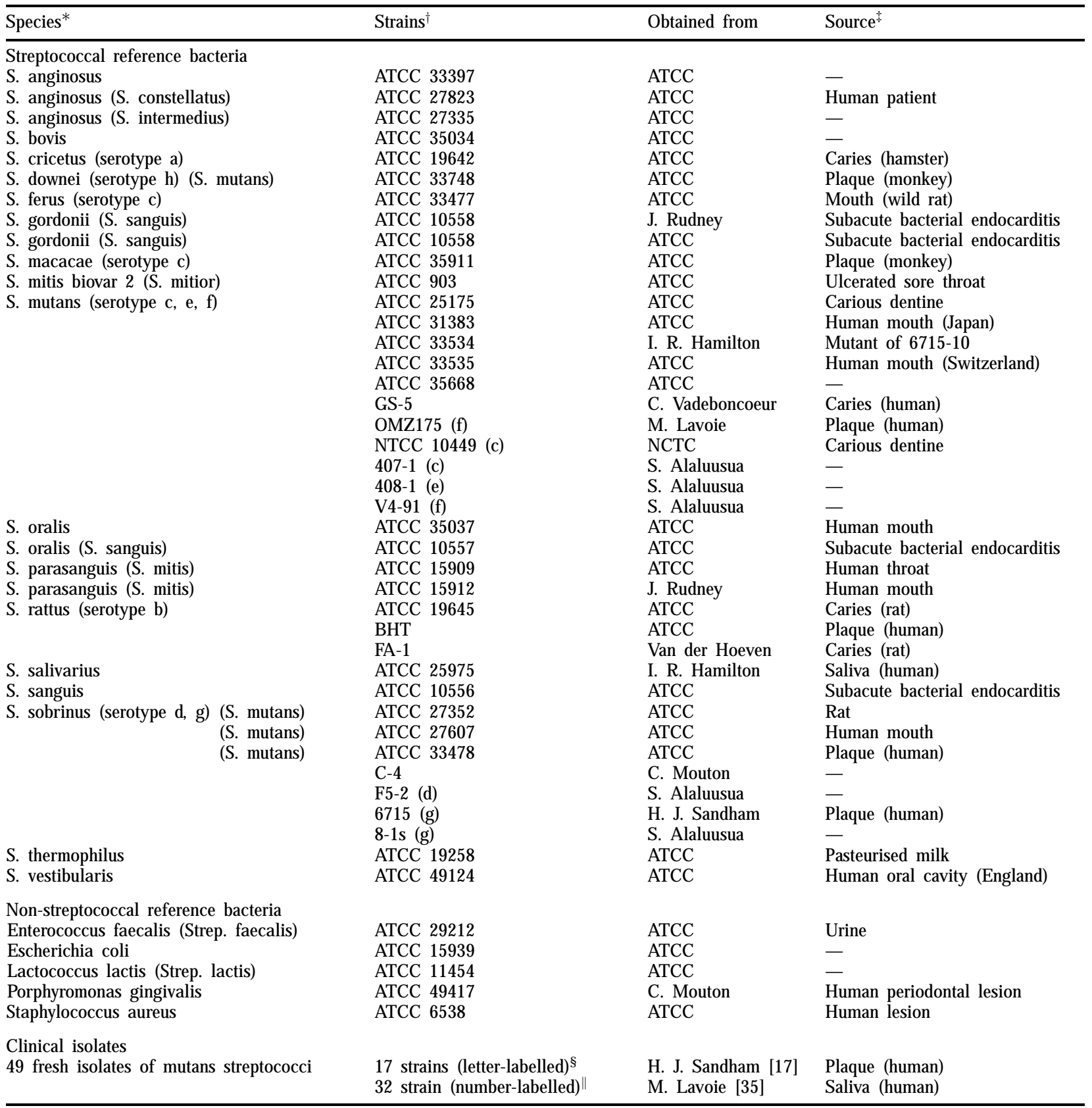

*The current taxonomic position of the bacteria is indicated together with, when applicable, the name (in parentheses) they were given when first deposited at the ATCC.

tThe serotype of the bacteria from the mutans streptococci group is indicated in parentheses when known.

The source of the bacteria is given when known.

${ }^{\S}$ Each of these 17 letter-labelled mutans streptococci isolates had a unique REA fingerprint [17].

$\|$ Each of these 32 number-labelled isolates was characterised as S. mutans [35].

and two minor ones (Fig. 1). This set of amplicons was common to all the reference strains of $S$. mutans tested, except for strains ATCC 31383 and 33534. Strain ATCC 31383 more closely resembled S. rattus than S. mutans, as three of the five amplicons generated by primer $970-11$ were common to all S. rattus strains tested. This resemblance to $S$. rattus was also demonstrated with primers OPA-18 (Fig. 1) and OPA-9 (data not shown), although a perfect match with the typical S. rattus RAPD patterns was not obtained. Moreover, the A PI Rapid Strep ${ }^{\mathbb{R}}$ test does not clearly identify this strain as a member of the mutans streptococci.
The RAPD profiles of strain ATCC 33534 (also named DR 0001) were also quite distinct from the characteristic pattern of $\mathrm{S}$. mutans (Fig. 1). A group of amplicons were ATCC 33534 strain-specific; other discrete amplicons were shared with other taxa of the mutans streptococci group, e.g., $990 \mathrm{bp}$ (immediately above the 977-bp amplicon) obtained with primer 97011,955 bp with OPA -3 and 1660 bp with OPA -18. This genotypically uncharacteristic S. mutans ATCC 33534 showed a fermentation pattern similar to that of $S$. mutans strains, but failed to metabolise melibiose (data not shown). 


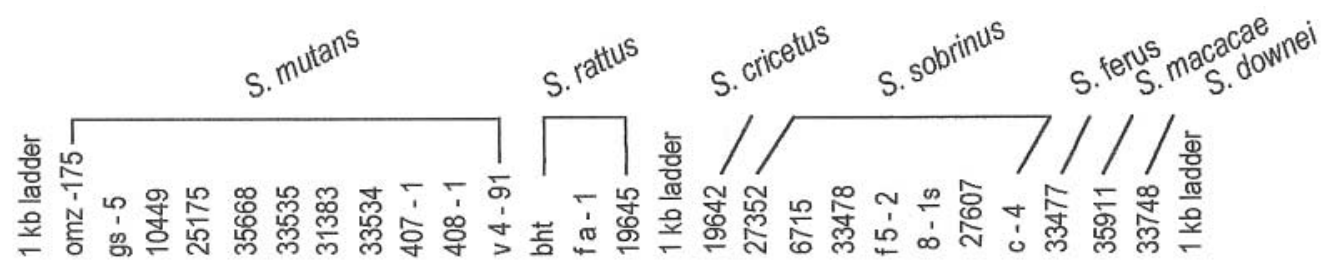

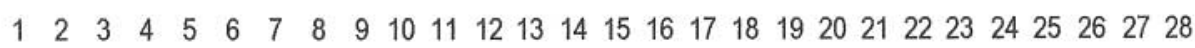
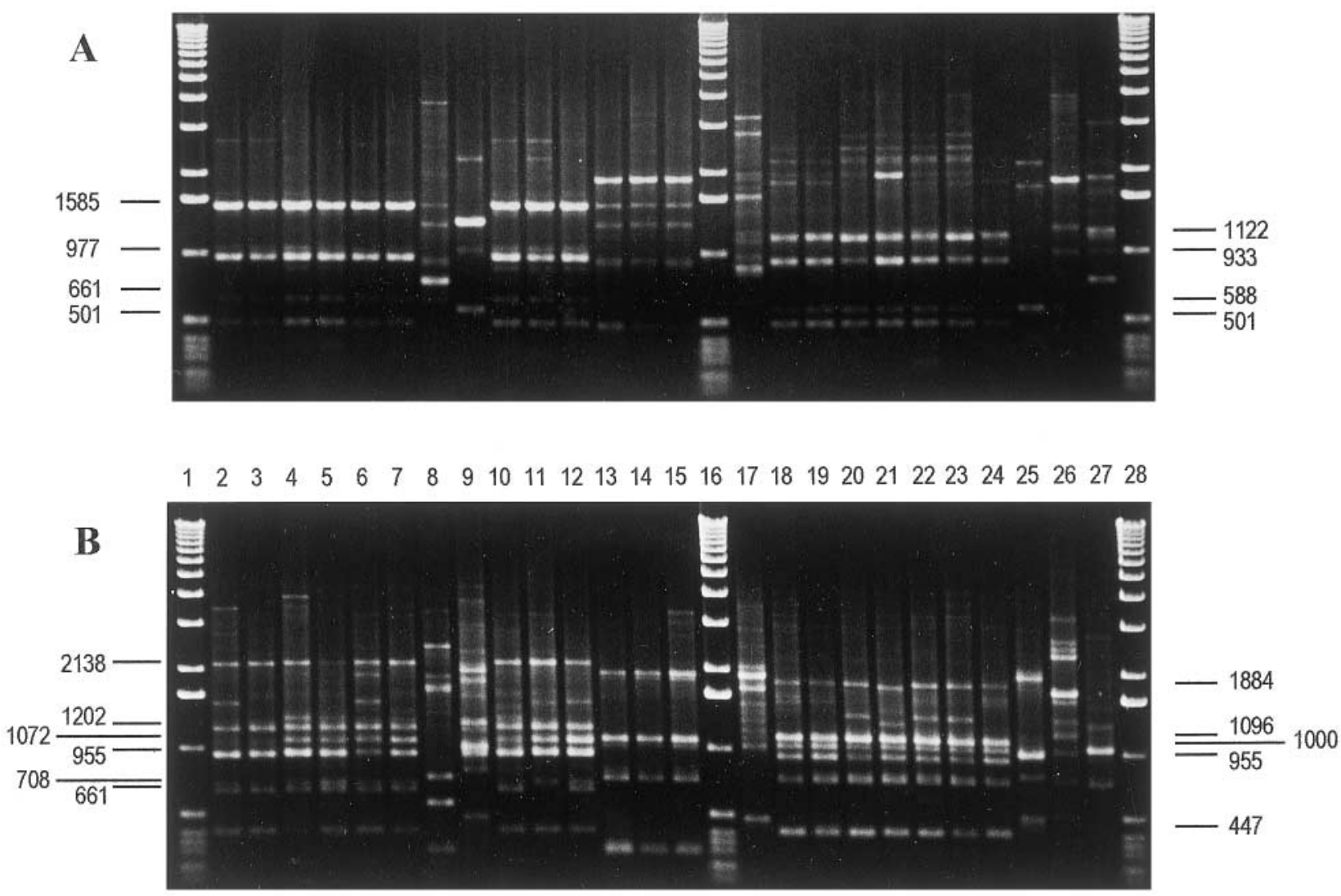

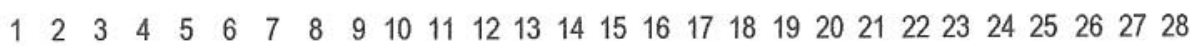

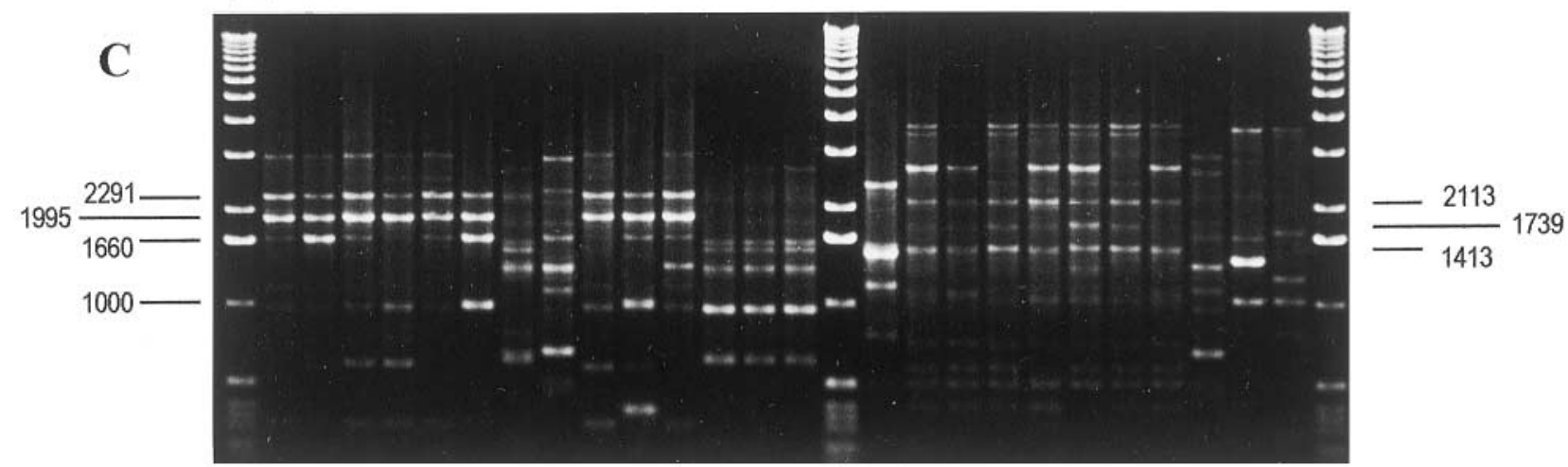

Fig. 1. RAPD fingerprints obtained with the reference strains of the mutans streptococci group. When possible, more than one strain of each species was included in the study. Species names in labels are based on published results and phenotypic studies as described in Materials and methods. Purified DNA was amplified with the arbitrarily selected primers 970-11 (A), OPA-3 (B) and OPA-18 (C) as described in Materials and methods. M ol. wt markers (1-kb ladder) are in bp. Marked sizes indicate amplicons that constitute a distinctive set characteristic of the species $\mathrm{S}$. mutans (lefthand side) and S. sobrinus (right-hand side).

Use of primers OPA-3 and OPA-18 also yielded a specific fingerprint for $\mathrm{S}$. mutans strains so far tested. Each of these primers generated a short spectrum of amplicons, located between 661- and 2291-bp markers, indicative of genetic polymorphism. A set of major amplicons at 2138, 1202 and $955 \mathrm{bp}$ as generated by OPA -3, and at 2291 and $1995 \mathrm{bp}$ as obtained with OPA-18 (Fig. 1), were shared by all strains of $\mathrm{S}$. 


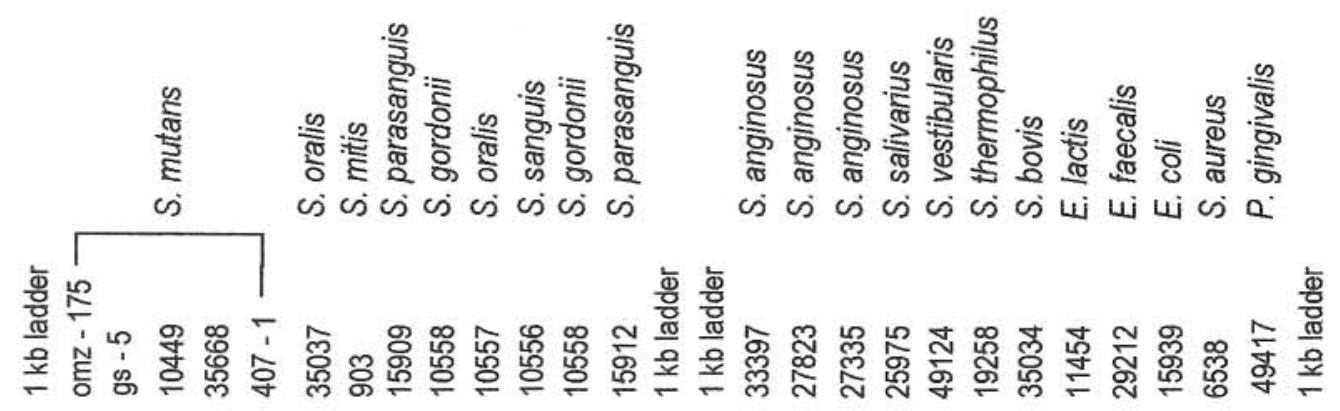

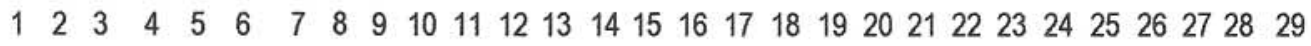

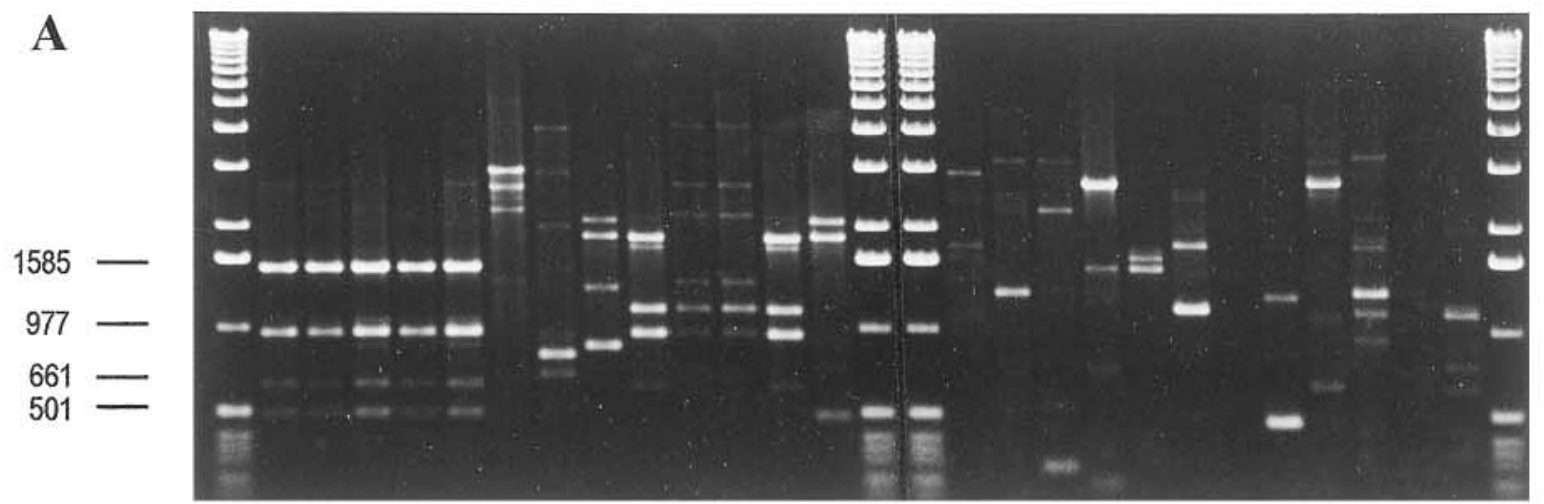

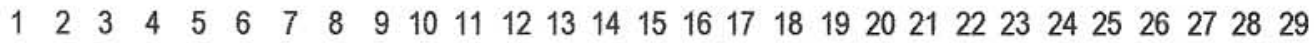

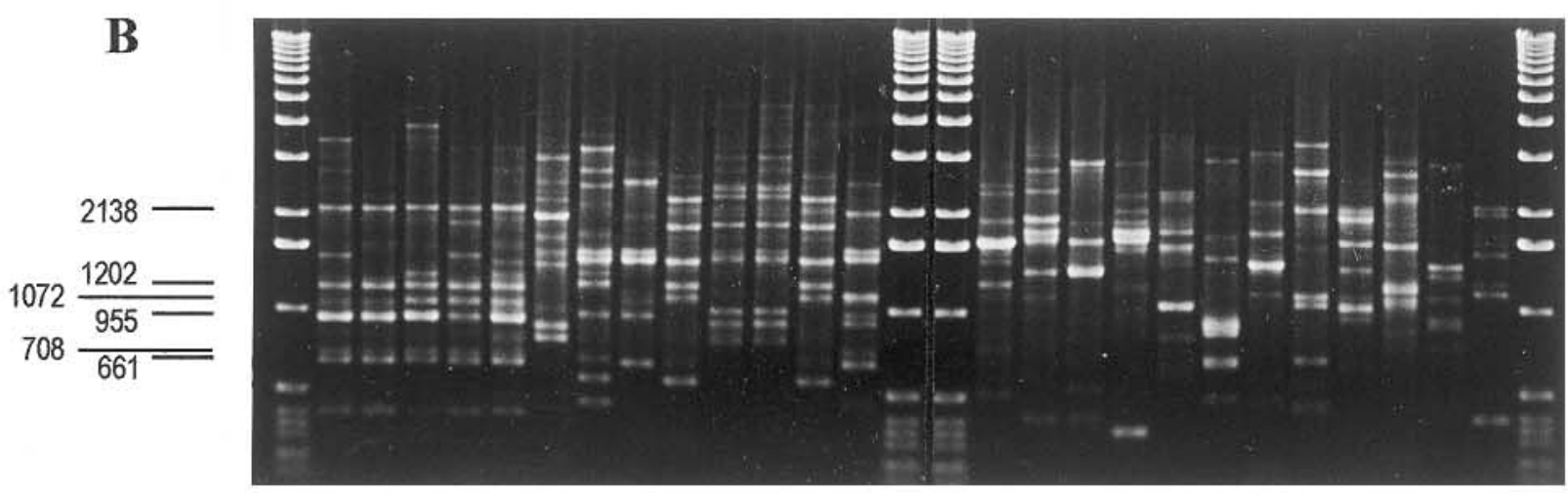

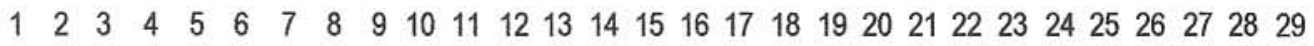

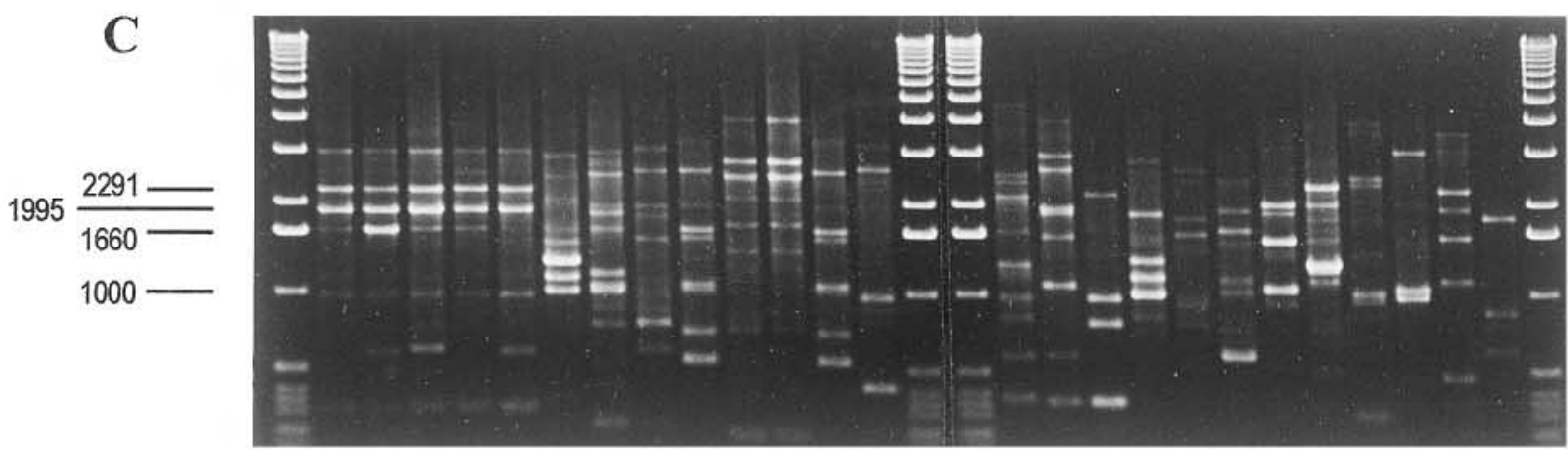

Fig. 2. RAPD fingerprints of $\mathrm{S}$. mutans, other streptococci and a few other unrelated species. Species names in labels and procedures were as indicated in Fig. 1 and Materials and methods. Mol. wt markers (1-kb ladder) are in bp. $M$ arked sizes indicate amplicons that constitute a distinctive set characteristic of the species $S$. mutans. 
mutans, except for strains ATCC 31383 and 33534, as for the set of amplicons generated by primer 970-11.

Overall, the fingerprints obtained from $\mathrm{S}$. mutans with the selected primers were unique and species-specific. This unique signature was ascertained not only by comparison with other species within the mutans streptococci group (Fig. 1), but also with other streptococci and unrelated species (Fig. 2) within the limits of the small number of strains analysed. The fingerprints were thus helpful for strain identification and distinction.

The S. sobrinus RAPD fingerprints contained sets of major amplicons that were shared by all reference strains (Fig. 1). With primer 970-11, a quadruplet of bands located at 1122, 933, 588 and 501 bp characterised an S. sobrinus genotype which was clearly distinct from related (Fig. 1) and unrelated (Fig. 2) species, again within the limits of the number of strains tested. Use of primers OPA-3 or OPA-18 yielded a characteristic signature for $\mathrm{S}$. sobrinus as a pattern located between 447 and 1884 bp (OPA-3) or between 1413 and 2113 bp (OPA-18).

Although the fingerprints of $S$. mutans and $S$. sobrinus were quite distinct pairwise, the observation of a shared amplicon in the RAPD profile was indicative of some degree of genetic relatedness, as revealed by the sharing of common amplicons by all strains of these two species tested. In Fig. 1, it can be seen that amplicons located at $501 \mathrm{bp}$ and at $955 \mathrm{bp}$, obtained with primers 970-11 and OPA-3, respectively, were common to all reference strains of $S$. mutans and $S$. sobrinus tested in this study.

RAPD fingerprinting of clinical isolates of mutans streptococci and of S. mutans

A total of 49 isolates, together with S. mutans reference strain NCTC 10449, were compared in RAPD with primers 970-11, OPA-3 and OPA-18, and typical RAPD patterns are presented in Fig. 3. The characteristic RAPD profiles unique to $S$. mutans, as defined with the reference strains (Figs. 1 and 2), were found in 46 of the 49 isolates tested. All three isolates which showed patterns quite different from the typical RAPD profiles of $\mathrm{S}$. mutans were from the 17 letterlabelled samples identified as mutans streptococci: B smooth (Bs), $\mathrm{H}$ and $\mathrm{O}$. Each of the 32 number-labelled isolates characterised as $\mathrm{S}$. mutans showed the RAPD profiles unique to $S$. mutans. Strain Bs showed a close resemblance to the $S$. sobrinus reference strains based on a comparison of the banding patterns obtained with primers 970-11 and OPA-3. A re-examination of this strain $B$ s revealed that it was morphologically different from strain B, from which it had been isolated, and biochemical tests confirmed this strain as $\mathrm{S}$. sobrinus. Strains $\mathrm{H}$ and $\mathrm{O}$ had distinct patterns that did not correspond to any of the reference strains tested. The
API Rapid Strep ${ }^{\circledR}$ test identified isolates Bs and $\mathrm{H}$ as mutans streptococci and isolate $\mathrm{O}$ as $\mathrm{S}$. sanguis.

The white $(\mathrm{J} w)$ and yellow $(\mathrm{J})$ variants of isolate J showed the amplicons generated by all three primers that characterise the $\mathrm{S}$. mutans species. However, they were distinguished from one another by extra amplicons generated by primer OPA -3 and by a preferential amplification of the 1660-bp amplicon generated by primer OPA-18. It can also be seen in Fig. 3 that the presence or absence of some of the amplicons generated by the three primers or the intensity of the fluorescence of other amplicons distinguishes some $S$. mutans strains from the others. This indicates that sets of amplicons can be used to identify the S. mutans species and others may possibly detect the clonal type.

\section{AP-PCR on broth cultures and colonies}

Whole-cell extracts from broth cultures and colonies were used as DNA templates in the AP-PCR procedure with primers 970-11, OPA-3 and OPA-18 (results not shown). Of all the amplicons obtained with the corresponding purified DNA preparations, only those $>2.9 \mathrm{~kb}$ in size, when primer OPA-3 was used, were not found when crude cellular or colony extracts were used as DNA templates. The RAPD patterns characteristic of $S$. mutans species obtained with pure DNA were otherwise generated. Comparison of the patterns obtained from corresponding broth culture and colony extracts shows differences in the 'cleanness' and the quantity of the amplification products. These could possibly be explained by variations in the size of the colonies used for the extractions as compared with the more constant cell number found in the overnight cultures used for the broth extracts, as suggested by others [38].

\section{Discussion}

It has been shown that the polymorphism in length of the amplified sequences (amplicons) of RAPD fingerprints obtained by AP-PCR can be used to compare bacterial strains [22-24], including the groups of mutans streptococci $[28,29]$ and mitis streptococci [30]. In the present study, this application of RAPD analysis to genotyping of oral streptococci confirmed that the RAPD assay can distinguish the species $\mathrm{S}$. mutans and S. sobrinus from each other. Moreover, despite the small number of reference strains tested, the data suggest that the RAPD assay can distinguish these species from other oral streptococci, as fingerprints unique to $\mathrm{S}$. mutans or $\mathrm{S}$. sobrinus strains could be generated with several primers. As previously demonstrated by Saarela et al. [28] for cell lysates the study also showed that RAPD fingerprints similar to those obtained with pure genomic DNA could be generated from crude broth culture and colony extracts. 

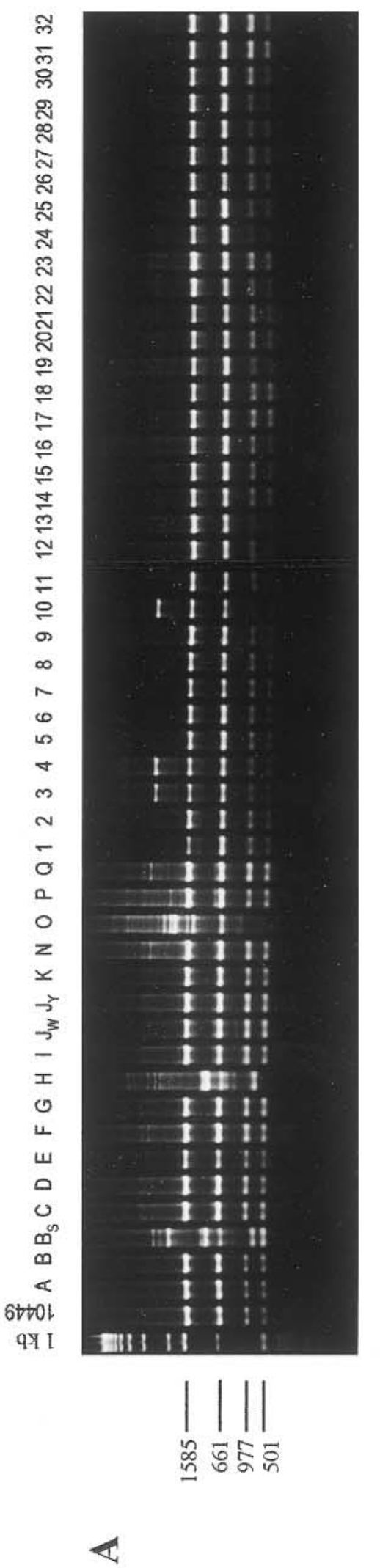
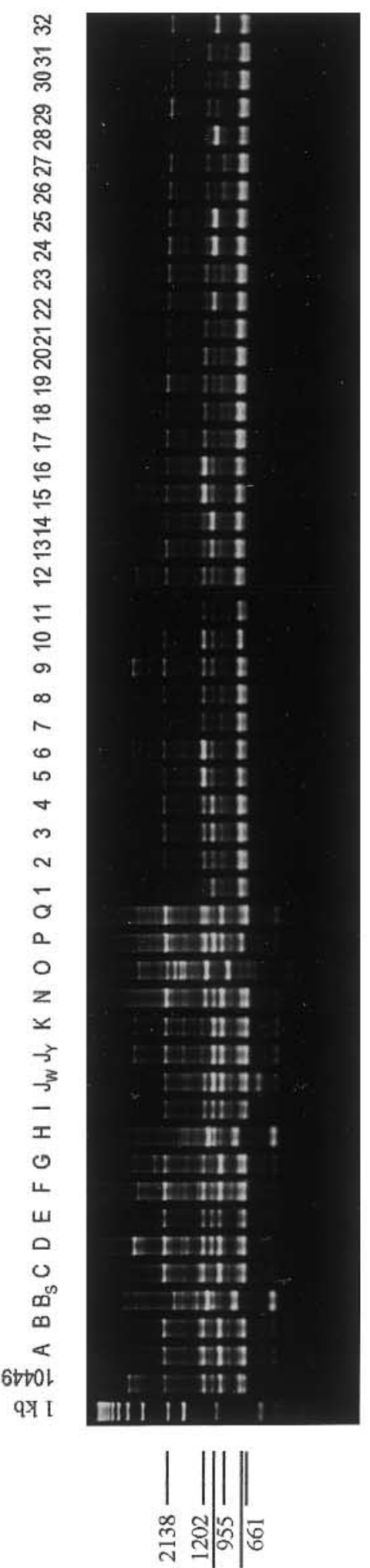

농
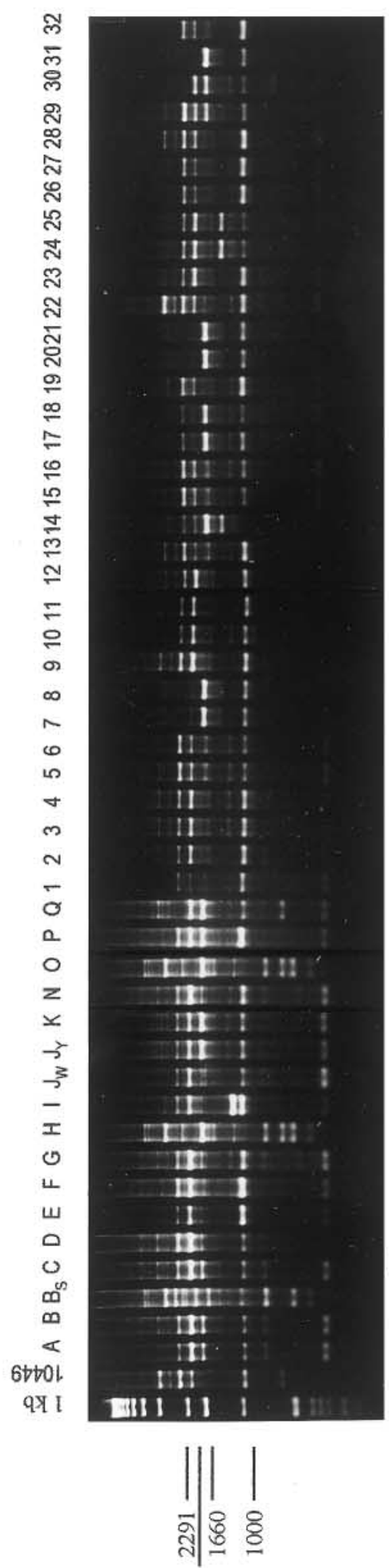

gั

Fig. 3. RAPD fingerprints of clinical isolates of mutans streptococci. The procedure was as indicated in Fig. 1 and Materials and methods. Reference strain S. mutans NCTC 10449 was included as a positive control. Mol. wt markers and indicated sizes are as in Fig. 2. Letter-labelled isolates identified as mutans streptococci were from dental plaque [17] and number-labelled isolates characterised as S. mutans were from saliva [35]. 
RAPD performed on $S$. mutans reference strains and on 49 clinical isolates (Figs. 1, 2 and 3) showed, with very few exceptions, that a fingerprint unique for the species could be obtained. This RAPD fingerprint was highly specific to $S$. mutans and its reproducibility was excellent, not only between DNA extractions of a given strain, but also from one experiment to the next - as can be seen with strain 104449 in Figs. 1, 2 and 3. Divergence from the typical $S$. mutans profile of strain ATCC 31383 suggests that this strain should no longer be considered as S. mutans. As the banding pattern of ATCC 31383 showed a closer resemblance to all three S. rattus strains so far tested - although a perfect match with the typical S. rattus RAPD patterns was not obtained - it may be that strain ATCC 31383 represents a clonal group within the $\mathrm{S}$. rattus taxon. With regard to strain ATCC 33534, it has been suggested recently that melibiose-negative strains would represent a cryptic species in the S. mutans taxon [21].

Although only one strain each of S. cricetus, S. ferus, $\mathrm{S}$. macacae and $\mathrm{S}$. downei were tested in the present study, it can already be seen that a specific characteristic RAPD profile could be constructed for each of the seven species within the group of mutans streptococci (Fig. 1). Such profiles, if corroborated by the analysis of numerous other strains, would then correspond to and confirm the diversity of this group of oral streptococci, as well described by Coykendall [1]. Likewise, Rudney and Larson [30] have shown recently that RAPD allows rapid identification of genotypic groups corresponding closely to mitis group species established by phenotype.

Furthermore, the polymorphism in length of amplicons of such RAPD profiles allowed not only for species identification and distinction between $\mathrm{S}$. mutans and $\mathrm{S}$. sobrinus, but also possibly indicated relatedness between species of the mutans streptococci group. For instance, with primer 970-11, it can be seen that the 977-bp amplicon is common to all S. mutans strains tested, an indication that it could be used as a speciesspecific marker. On the other hand, amplicons are shared with other species: the 1585-bp amplicon shared with $\mathrm{S}$. rattus and the discrete 501-bp amplicon shared with $\mathrm{S}$. rattus and $\mathrm{S}$. sobrinus. This relatedness between taxa within the viridans streptococci family and divergence in taxonomic structures merits a more complete and sophisticated approach than the visual analysis used here. In addition to analysis of a much greater number of strains, a cluster assisted analysis with Lance and Williams genetic distance algorithm to construct the dendrogram (phenogram) for all groups of viridans streptococci could be applied, as in a previous work to construct a biotyping scheme for Porphyromonas gingivalis [39].

It was possible to distinguish the white ( $\mathrm{W}$ ) and yellow (J y) variants of isolate J from one another (Fig. 3). Such data suggest that sets of amplicons can be used to discriminate between clonal types. Like other studies [28], the present study could not differentiate between serotypes of $S$. mutans as, irrespective of the primer used, the unique RA PD patterns obtained with serotype c, e, or $f$ of $S$. mutans so far tested were similar. Thus it would appear that the division of strains of mutans streptococci into serogroups has little relation to the underlying genetic structure of the species. This lack of relationship has also been shown for P. gingivalis [40, 41].

The 17 letter-labelled clinical isolates of mutans streptococci from eight patients, each of which had a unique REA fingerprint [17], were also identified by a single genetic pattern with the three working primers. As the RAPD profiles have only a small number of bands and, consequently, are much easier to read than the corresponding REA patterns, they should be considered helpful for epidemiological and transmission studies of mutans and other oral streptococci, as al ready shown with P. gingivalis [27] and suggested for mutans streptococci $[28,29]$.

In this study, three working primers were selected from among 56 tested for their capacity to differentiate mutans streptococci. It should be noted that if these primers showed useful similarities between the RAPD profiles of almost all 15 reference and 49 clinical $S$. mutans strains tested (Figs. 1 and 3), they also showed dissimilarities between strains of some of the nonmutans streptococci species tested, as shown in Fig. 2 for S. oralis, for example. Moreover, they showed similar profiles for S. oralis 10557 and S. sanguis 10556. This highlights the limitations of the selected primers for certain species. However, it must also be recognised that the identity of these strains of $\mathrm{S}$. oralis and $\mathrm{S}$. sanguis have always been problematic - as demonstrated by their reclassification as shown in Table 1. The RAPD profiles obtained in this study suggest that $\mathrm{S}$. oralis 10557 might indeed be an S. sanguis strain as previously established. This also stresses the need for confirmation of identifications by other methods.

In this study, fingerprints were compared for similarity by eye and the molecular sizes of the major amplicons were assigned by hand. It is clear that the handling of large numbers of polymorphic banding patterns for molecular systematics would benefit from improvements, for the detection of and discrimination between amplicons, resulting from the use of computer-integrated densitometry for band sizing and computerassisted image capture, data storage and analysis methods, as suggested previously [41].

In summary, the data indicate that AP-PCR can generate characteristic and unique RAPD fingerprints that are highly specific for $\mathrm{S}$. mutans and $\mathrm{S}$. sobrinus from both purified DNA and crude cellular or colony extracts. From these data it can be anticipated that a 
working RAPD protocol could be used: (i) to distinguish the species $\mathrm{S}$. mutans and $\mathrm{S}$. sobrinus from other species of oral streptococci, and (ii) to possibly identify and sub-classify all oral streptococci. The data also confirm that RAPD fingerprinting is a potentially valuable tool in bacterial epidemiology and transmission studies of oral streptococci by virtue of its rapidity, efficiency and reproducibility in exploring the genomic polymorphism of these organisms.

We acknowledge the capable technical assistance of Gene Bourgeau and Marjolaine Thiffeault. We thank the collaborators mentioned in Table 1 for providing the indicated strains. This work was supported by grants MT-12077 and MA-8761 from the Medical Research Council of Canada and by the Fonds Émile-Beaulieu.

\section{R eferences}

1. Coykendall AL. Classification and identification of the viridans streptococci. Clin Microbiol Rev 1989; 2: 315-328.

2. Hamada S, Slade HD. Biology, immunology, and cariogenicity of Streptococcus mutans. Microbiol Rev 1980; 44: 331-384.

3. Loesche WJ. Role of Streptococcus mutans in human dental decay. Microbiol Rev 1986; 56: 353-380.

4. Hardie JM, Marsh PD. Oral streptococci. London Society for Applied Bacteriology Symposium 1978; Series no. 7: 380- 383.

5. Kilian M, Mikkelsen L, Henrichsen J. Taxonomy study of viridans streptococci: description of Streptococcus gordinii sp. nov. and emended descriptions of Streptococcus sanguis (W hite and Niven 1946), Streptococcus oralis (Bridge and Smeath 1982) and Streptococcus mitis (Andrewes and Horder 1906). Int J Syst Bacteriol 1989; 39: 471-484.

6. Beighton D, Hardie JM, Whiley RA. A scheme for the identification of viridans streptococci. J Med Microbiol 1991; 35: 367-372.

7. Bratthall D. Demonstration of five serological groups of streptococcal strains resembling Streptococcus mutans. Odont Rev 1970; 21: 143-152.

8. Coykendall AL. Four types of Streptococcus mutans based on their genetic, antigenic and biochemical characteristics. J Gen Microbiol 1974; 83: 327-338.

9. Facklam RR. Physiological differentiation of viridans streptococci. I Clin Microbiol 1977; 5: 184-201.

10. Hardie JM, Bowden GH. Physiological classification of oral viridans streptococci. J Dent Res 1976; 55: A 166-A 176.

11. Shklair IL, Keene HJ. A biochemical scheme for the separation of the five varieties of Streptococcus mutans. Arch Oral Biol 1974; 19: 1079- 1081.

12. Coykendall AL. Genetic heterogeneity in Streptococcus mutans. I Bacteriol 1971; 106: 192-196.

13. Facklam RR. The major differences in the American and B ritish Streptococcus taxonomy schemes with special reference to Streptococcus milleri. Eur J Clin Microbiol 1984; 3: 91-93.

14. Coykendall AL, Gustafson KB. Taxonomy of Streptococcus mutans. In: Hamada S, Michalek SM, Kiyono H, M enaker L, $M c G$ hee JR (eds) Molecular microbiology and immunobiology of Steptococcus mutans. Amsterdam, Elsevier Science. 1986: 21- 28.

15. Schleifer KH, Kilpper-Bälz R. Molecular and chemotaxonomic approaches to the classification of streptococci, enterococci, and lactococci: a review. System Appl Microbiol 1987; 10: 1-19.

16. Caufield PE, Walker TM. Genetic diversity within Streptococcus mutans evident from chromosomal DNA restriction fragment polymorphisms. J Clin Microbiol 1989; 27: 274-278.

17. Kozai K, Wang DS, Sandham HJ, Philips HI. Changes in strains of mutans streptococci induced by treatment with chlorexidine varnish. J Dent Res 1991; 70: 1252-1257.

18. Kulkarni GV, Chan KH, Sandham HJ. Investigation into the use of restriction endonuclease analysis for the study of transmission of mutans streptococci. J Dent Res 1989; 68: $1155-1161$

19. Saarela M, Alaluusua S, Takei T, A sikainen S. Genetic diversity within isolates of mutans streptococci recognized by an rRNA gene probe. J Clin Microbiol 1993; 31: 584-587.

20. Gilmour MN, Whittam TS, Kilian M, Selander RK. Genetic relationships among the oral streptococci. I Bacteriol 1987; 169: 5247-5257.

21. Colby SM, Harrington DJ, Russell RR. Identification and genetic characterisation of melibiose-negative isolates of Streptococcus mutans. Caries Res 1995; 29: 407-412.

22. Welsh J, MCClelland M. Fingerprinting genomes using PCR with arbitrary primers. Nucleic Acids Res 1990; 18: 72137218.

23. Williams JGK, Kubelik AR, Livak KJ, Rafalski JA, Tingey SV. DNA polymorphisms amplified by arbitrary primers are useful as genetic markers. Nucleic Acids Res 1990; 18: 6531-6535.

24. M énard $C, B$ rousseau $R$, M outon $C$. A pplication of polymerase chain reaction with arbitrary primer (AP-PCR) to strain identification of Porphyromonas (Bacteroides) gingivalis. FEMS Microbiol Lett 1992; 95: 163-168.

25. M énard C, M outon C. Randomly amplified polymorphic DNA analysis confirms the biotyping scheme of Porphyromonas gingivalis. Res Microbiol 1993; 144: 445- 455.

26. Preus HR, Haraszthy VI, Zambon JJ, Genco RJ. Differentiation of strains of Actinobacillus actinomycetemcomitans by arbitrarily primed polymerase chain reaction. I Clin Microbiol 1993; 31: 2773- 2776.

27. van Steenbergen TMJ, M énard $C$, Tijhof $C$ J, M outon $C$, de Graaff J. Comparison of three molecular typing methods in studies of transmission of Porphyromonas gingivalis. J Med Microbiol 1993; 39: 416-421.

28. Saarela M, Hannula J, Mättö J, A sikainen $S$, Alaluusua $S$. Typing of mutans streptococci by arbitrarily primed polymerase chain reaction. Arch Oral Biol 1996; 41: 821-826.

29. Li Y, Caufield PW. A rbitrarily primed polymerase chain reaction fingerprinting for the genotypic identification of mutans streptococci from humans. Oral Microbiol Immunol 1998; 13: 17-22.

30. Rudney JD, Larson CJ. Identification of oral mitis group streptococci by arbitrarily primed polymerase chain reaction. Oral Microbiol Immunol 1999; 14: 33-42.

31. Gardiner D, Hartas J, Currie B, Mathews JD, Kemp DJ, Sriprakash KS. Vir typing: a long-PCR typing method for group A streptococci. PCR M ethods Appl 1995; 4: 288-293.

32. Jayarao BM, Bassam BJ, Caetano-A nollés G, Gresshoff PM Oliver SP. Subtyping of Streptococcus uberis by DNA amplification fingerprinting. J Clin Microbiol 1992; 30: 1347-1350.

33. Österlund A, Engstrand L. DNA fingerprinting of Streptococcus pyogenes from patients with recurrent pharyngotonsillitis by means of random amplified polymorphic DNA analysis. Scand J Infect Dis 1995; 27: 119-221.

34. Seppälä H, He Q, Österblad M, Huovinen P. Typing of group A streptococci by random amplified polymorphic DNA analysis. J Clin Microbiol 1994; 32: 1945- 1948.

35. Parrot $M$, Dréan $M-F$, Trahan $L$, Lavoie $M C$. Incidence of bacteriocinogeny among fresh isolates of Streptococcus mutans. Can J Microbiol 1990; 36: 507-509.

36. Chassy BM, Giuffrida A. Method for the lysis of Grampositive, asporogenous bacteria with lysozyme. Appl Environ Microbiol 1980; 39: 153-158.

37. Smith GLF, Socransky SS, Smith CM. Rapid method for the purification of DNA from subgingival microorganisms. Oral Microbiol Immunol 1989; 4: 47-51.

38. Tyler KD, Wang G, Tyler SD, Johnson WM. Factors affecting reliability and reproducibility of amplification-based DNA fingerprinting of representative bacterial pathogens. J Clin Microbiol 1997; 35: 339-346

39. Mouton $C, M$ énard $C$. DNA fingerprinting of Porphyromonas gingivalis by arbitrarily primed PCR. In: Genco R, Hamada $S$ Lehner T, McGhee J, Mergenhagen $S$ (eds) Molecular pathogenesis of periodontal disease. Washington, A merican Society for Microbiology. 1994: 33- 46.

40. Loos BG, Dyer DW, Whittam TS, Selander RK. Genetic structure of populations of Porphyromonas gingivalis associated with periodontitis and other oral infections. Infect Immun 1993; 61: 204-212.

41. Ménard C, Mouton C. Clonal diversity of the taxon Porphyromonas gingivalis assessed by random amplified polymorphic DNA fingerprinting. Infect Immun 1995; 63: 2522- 2531. 